\title{
The Database of the Active Faults of Eurasia (AFEAD): Ontology and Design behind the Continental-Scale Dataset
}

\author{
Egor Zelenin $^{1}$, Dmitry Bachmanov ${ }^{1}$, Sofya Garipova ${ }^{1}$, Vladimir Trifonov ${ }^{1}$, Andrey Kozhurin ${ }^{2,1}$ \\ ${ }^{1}$ Geological Institute, Moscow, 119017, Russia \\ $5 \quad$ Institute of Volcanology and Seismology, Petropavlovsk-Kamchatsky, 683006, Russia
}

Correspondence to: Egor Zelenin (egor.zelenin@ginras.ru)

\begin{abstract}
.
Active faults are those faults on which movement is possible in the future. It draws particular attention to active faults in geodynamic studies and seismic hazard assessment. Here we present a high-detail continental-scale geodatabase: The Active

10 Faults of Eurasia Database (AFEAD). It comprises 46,775 objects stored in the shapefile format with spatial detail sufficient for a map of scale 1:1M. Fault sense, a rank of confidence in activity, a rank of slip rate, and a reference to source publications are provided for each database entry. Where possible, it is supplemented with a fault name, fault zone name, abbreviated fault parameters (e.g., slip rate, age of the last motion, total offset), and text information from the sources. The database was collected from 612 sources, including regional maps, databases, and research papers.

15 AFEAD facilitates a spatial search for local studies. It provides sufficient detail for planning a study of a particular fault system and guides deeper bibliographical investigations if needed. This scenario is particularly significant for vast Central and North Asia areas, where most studies are available only in Russian and hardcopy. Moreover, the database model provides the basis for GIS-based regional and continental-scale integrative studies.

The database is available at https://doi.org/10.13140/RG.2.2.10333.74726 and via web map at

20 http://neotec.ginras.ru/index/mapbox/database_map.html (last access: July 30, 2021). Some database representations with supplementary data are hosted at http://neotec.ginras.ru/index/english/database_eng.html.
\end{abstract}

\section{Introduction}

The concept of an active fault emerged to distinguish a specific group of faults with present tectonic movements and hence with anticipated activity in the nearest future. The term "active fault" and its synonym "living fault" were introduced in the late 1940s to 1950s by both American and European authors (Wallace, 1949; Geologische Rundschau, 1955). This group of faults has a particular significance in two aspects of geological studies. The slip at the fault produces an earthquake; thus, active faults are a crucial component of seismic hazard assessment (Ulomov et al., 1993; Basili et al., 2013; Walker et al., 2021). Moreover, active faulting occurs simultaneously across the Earth and thus provides a basis for studies of recent geodynamics (e.g., Rukieh et al., 2005; Schellart and Lister, 2005; Kozhurin and Zelenin, 2017). 
30 The first global-scale inventory of active faults was the ILP Project II-2 World Map of Major Active Faults initiated in 1989 and included in the ILP Global Seismic Hazard Assessment Program in 1993. The Project II-2 joined more than 70 scientists from 50 countries lead by two co-chairmen representatives for the Eastern (V.G. Trifonov) and Western (M.S. Machette) Hemispheres. The Geological Institute of the Russian Academy of Sciences, Moscow, hosted the data on active faults of Eurasia provided by project members. These source data were represented in different scales and formats (maps, tables,

35 descriptions, and papers), so the first database (DB96) of active faults of Eurasia (Ioffe et al., 1993; Ioffe and Kozhurin, 1996; Trifonov, 1997) was intended to store digitized fault geometry in uniform scale (1:5M) and with a unified set of attributes. Recent advances in tectonics and IT highlighted the limitations of DB96: that outdated database scheme became incompatible with modern GIS, the fault locations lacked accuracy, and many recently studied faults were to be incorporated.

40 All these issues required creating a conceptually new database, and this work was initiated based on DB96 some 15 years ago (Bachmanov et al., 2017). The authors have designed the new database and GIS for data processing that inherited all the strengths of DB96 but provided far more opportunities for parameterization and analysis. The result of this work is the Active Faults of Eurasia Database (AFEAD) presented in this paper (Fig. 1).

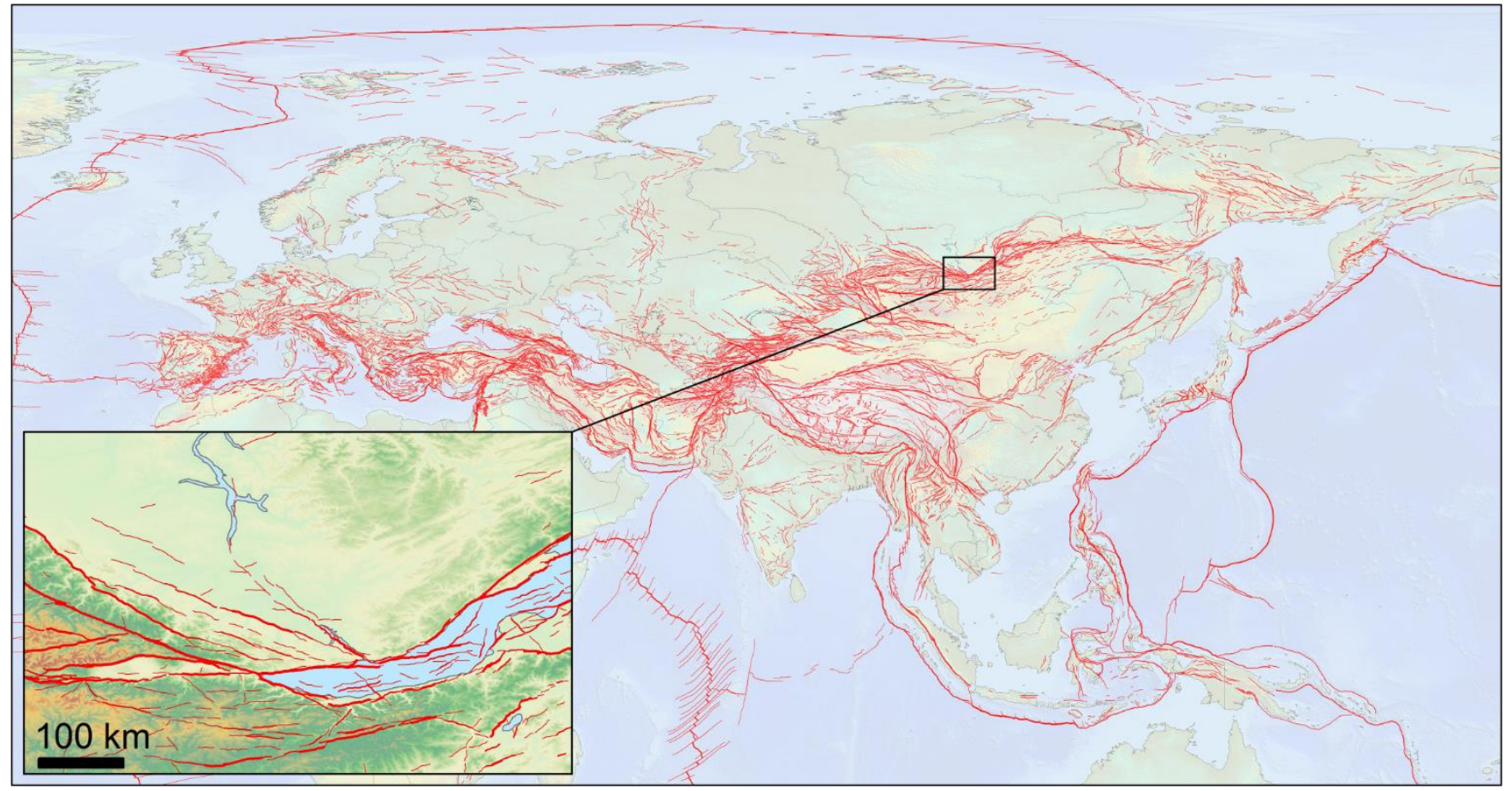

Figure 1: Overview and detail of the database of the active faults of Eurasia (AFEAD). 
https://doi.org/10.5194/essd-2021-312

Preprint. Discussion started: 5 October 2021

(c) Author(s) 2021. CC BY 4.0 License.

(c) (i)

\section{The Concept of an Active Fault}

Each object of the database represents an active fault. The meaning of this term varies significantly among studies; therefore, we consider it crucial to discuss what kind of data comprise the AFEAD.

From the most general approach, active faults are those faults on which movement is possible in the future (see discussion in

50 Slemmons and DePolo, 1986). Movements at the fault typically are intermittent, with strong earthquakes and long quiescence between them. The repose period generally is much longer than human's life, so that sole present-day observations cannot resolve uncertainty in fault activity, making it necessary to study the geological history of the fault.

The expectancy of future movement is what makes a fault active. All other fault parameters (such as kinematics, an average rate of movement, or any other) are intrinsic to faults in general, disregarding their age, and cannot affect the problem of

55 activity. The crucial question is what evidence could provide the basis for expecting future movements, and this question traditionally has been solved via the determination of a "critical" timespan back from the present during which at least one fault movement could have occurred. It is assumed that if such a movement has occurred, then the fault should be considered active. Estimations of the "critical" period were summarized by Galadini et al. (2012), and all the cited intervals fall within the range of 10,000 to 1,000,000 years. However, even longer intervals were discussed (e.g., 2.6 Ma by Atanackov et al.,

60 2021).

The concept of the critical interval implies that a slip may occur at an active fault after long quiescence. Paleoseismological studies, however, provide recurrence periods of hundreds to the first thousand years with maximum values of order tens ka. For example, Umehara Fault in Japan has a recurrence interval of 14-15 ka (Kumamoto, 1998). Indeed, further studies could reveal longer intervals, but even doubling or tripling this value limits the quiescence period within the Holocene and the Late

65 Pleistocene. Even in slow deforming continental regions, substantiated recurrence intervals fall within 20-30 ka (Bollinger et al., 2021). This estimate is close to Trifonov and Machette (1993) estimate for the World Map of Major Active Faults. Late Quaternary deformations remain on the Earth's surface and could be unambiguously distinguished when found at late Quaternary landforms. Therefore, remote sensing interpretation of recent landforms is sufficient for regional-scale mapping or paleoseismological fieldwork planning.

70 Identifying and mapping active faults must precede any detailed research, and many studies get results by sole remote sensing interpretation. We consider it reasonable to rely on satellite imagery accounting for the following limitations discussed by Trifonov and Kozhurin (2010): non-tectonic surface processes are unlikely to create a suspected linear landform; the older is the landform, the larger it is offset; all offsets have the same sense; fault sense is consistent with the fault pattern of the region.

75 The database authors make efforts to keep a balance between a unified representation of data and the intention to store all available data. Therefore, we propose a database model capable of indicating cases of a significantly different approach in studies. 


\section{Database Model}

The Active Faults of Eurasia Database is a geodatabase in the shapefile format, an open standard for geospatial vector data.

80 It stores the spatial location of fault lines on the Earth's surface and their attributes (Fig. 2). Within the attribute table, field order streamlines the workflow of the database population, so the fields organically form two groups. The first group contains fault parameters transferred from sources "as is" and is accompanied by a complete bibliographic reference. However, some unification was applied to these data to ensure the uniform glossary, spelling of fault names, and spatial detail. The second group of attributes, generated by the database owners, provide consistent nomenclature to simplify GIS processing.

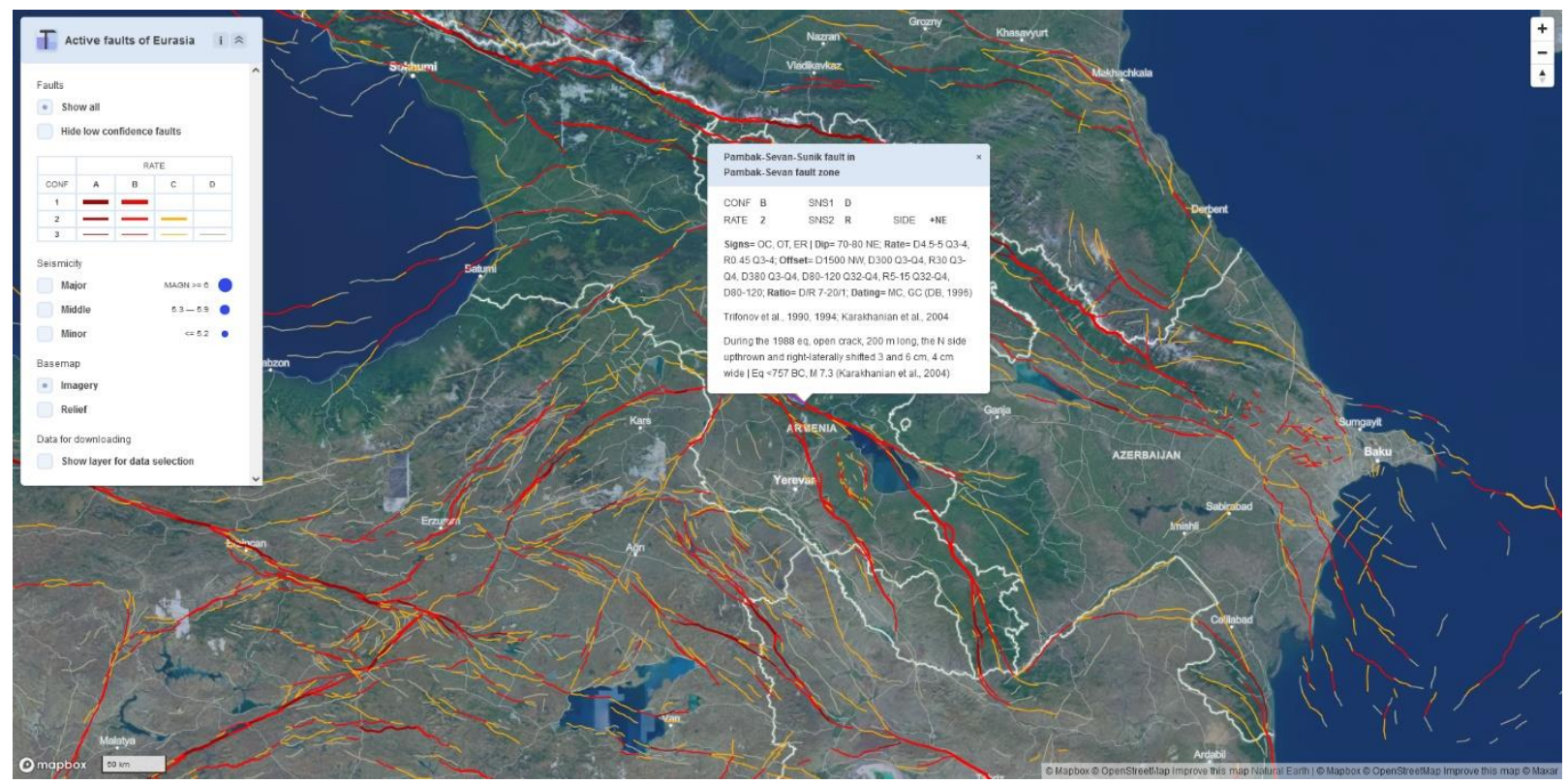

Figure 2. Spatial pattern of AFEAD faults in Transcaucasia with an attribute table for an object within the Pambak-Sevan fault. Snapshot of the AFEAD web-interface at http://neotec.ginras.ru/index/mapbox/database_map.html (last access: July 30, 2021).

\subsection{Geometry}

90 Every AFEAD record has a two-dimensional linear shape stored as a polyline. In most cases, it represents a fault Line crossing the Earth's surface and traced by scarp or a linear deformation of landforms, whereas some objects represent folds at the surface with an active fault revealed by geophysical or seismological studies below the Earth's surface. The spatial data populated from sources is processed to comply with the topography, the database model, and target map scale (1:1M). Usually, active fault deforms Earth's surface and may be traced on satellite imagery and digital elevation models. We

95 utilized the STRM global digital elevation model and Landsat 7 ETM+ imagery for georeferencing and spatial adjustment of published maps. In Soviet publications, the geographic location of studied objects was classified, so that processing of such data required deeper investigations and even reinterpretation of remote sensing data. 
All the objects in the database were redrawn at a scale of 1:500 000 with uniform spacing between vertices whenever possible, disregarding geometry accuracy in source data. Most of the fault lines bear attributes varying along it. In such cases, fault lines were split at the point where any attribute changes its value.

\subsection{Attributes Transferred from Source Data}

Collected data are stored in five fields: AUTH, FAULT_NAME, ZONE_NAME, PARM, and TEXT. Their order provides a workflow for data population, starting from identifying references and ending with auxiliary text data. This group of fields is supposed to store as much relevant data as possible and retain authors' interpretation. Still, some unification is applied to ensure the consistency of definitions and naming.

AUTH is a non-nullable field that stores brief English references to the studies considered that object. The field format complies with the reference list (see Sect. 3.4) for further bibliographic retrieval.

FAULT_NAME and ZONE_NAME store proper names of a fault and a fault zone, if available. In most cases, a fault zone includes a group of faults, either named or nameless. Name of a zone may originate from the name of its main fault, and an object with equal values of FAULT_NAME and ZONE_NAME should be interpreted as a main fault within a zone. If a fault has an ambiguous attribution to several fault zones, all of them are listed in ZONE_NAME, comma-separated. Uniform name spelling and designation of objects to a zone or a single fault are maintained in the database, even if varying among studies.

PARM is a formal description of fault parameters. It has a dictionary-like structure (Fig. 2, Appendix) with mnemonic keys ending with "=" and a comma-separated list of values after it. A sequence of keys from a single source is separated by semicolon, whereas different authorship is indicated with a vertical bar "l" and provided with the reference. For brevity, units of measurement are omitted with length reported in meters, depth in $\mathrm{km}$, rates in $\mathrm{mm} / \mathrm{yr}$, age in years BP or units of the geological time scale (e.g., N1 for the Miocene, Q4 for the Holocene), location in decimal degrees, unless otherwise stated explicitly. Acronyms are applied for directions and sense of slip (Table 1, Appendix). "Signs=", and "Dating=" have coded

120 values, the complete form provided in Appendix.

Table 1. Acronyms for fault sense used in the database.

\begin{tabular}{ll}
\hline $\mathrm{N}$ & Normal fault \\
$\mathrm{R}$ & Reverse fault \\
$\mathrm{T}$ & Thrust fault (reverse fault dipping $\left.<45^{\circ}\right)$ \\
$\mathrm{D}$ & Dextral (right-lateral) strike-slip fault \\
$\mathrm{S}$ & Sinistral (left-lateral) strike-slip fault \\
$\mathrm{E}$ & Extensional fracture \\
$\mathrm{V}$ & Dip-slip, sense unknown \\
$\mathrm{U}$ & Slip unknown \\
\hline
\end{tabular}


TEXT contains free-form comments on the fault characteristics supplementing other fields of this group.

\subsection{Derivative Attributes}

The derivative attributes are those produced by the database owners based on collected data. Data domain is defined for the fields of this group (Table 2), thus providing a basis for classification and spatial analysis. All of them, except for SENS2 and SIDE, are non-nullable.

Table 2. Values of derivative attributes.

\begin{tabular}{|c|c|c|}
\hline Attribute & Domain & Comments \\
\hline RATE & $\{1,2,3\}$ & $\begin{array}{l}1-\text { Measured rate exceeding } 5 \mathrm{~mm} / \mathrm{yr}, 2-1 \text { to } 5 \mathrm{~mm} / \mathrm{yr}, 3-\text { no } \\
\text { measured rate above } 1 \mathrm{~mm} / \mathrm{yr}\end{array}$ \\
\hline SENS1 & $\{\mathrm{N}, \mathrm{R}, \mathrm{T}, \mathrm{D}, \mathrm{S}, \mathrm{E}, \mathrm{V}, \mathrm{U}\}$ & Described in table 1 \\
\hline SENS2 & $\{\mathrm{N}, \mathrm{R}, \mathrm{T}, \mathrm{D}, \mathrm{S}, \mathrm{E}, \mathrm{V}$, null $\}$ & Described in table 1 \\
\hline SIDE & $\begin{array}{l}\{+\mathrm{N},+\mathrm{NE},+\mathrm{E},+\mathrm{SE},+\mathrm{S},+\mathrm{SW} \\
+\mathrm{W},+\mathrm{NW}, \text { null }\}\end{array}$ & Direction of the uplifted side \\
\hline CONF & $\{\mathrm{A}, \mathrm{B}, \mathrm{C}, \mathrm{D}\}$ & $\begin{array}{l}\text { A - proved active by a series of published either historical and } \\
\text { instrumental evidence or paleoseismological studies; } \\
\text { B - unambiguous surface deformations, but no recent slips have been } \\
\text { described yet; } \\
\text { C - few pieces of evidence of activity are known; } \\
\text { D - fault once stated active, but the evidence is insufficient or even } \\
\text { absent. }\end{array}$ \\
\hline
\end{tabular}

CONF indicates a level of confidence that a particular object once identified as an active fault meets the conventional definition of the active fault. Its variations represent the fact that the definition of the active fault varies between studies depending on their objectives and reasoning behind active fault mapping. In AFEAD, by "confidence" our team means a qualitative measure of expectance that an independent researcher would support the hypothesis of fault activity considering published evidence. We are aware that it is a highly ambiguous criterion, still crucial for representing a concept of an active fault, varying in meaning significantly. Following guidelines have been proposed for each class of CONF:

A - proved active by a series of published either historical and instrumental evidence or paleoseismological studies, multiple

135 crustal earthquakes occurred at the fault line consistent with fault sense;

B - unambiguous surface deformations, but no recent slips have been described yet, attribution of earthquakes is questionable;

$\mathrm{C}$ - few pieces of evidence of activity are known, lack of seismicity, surface deformations, or both;

$\mathrm{D}$-once declared active, but the evidence provided for such opinion is insufficient or even absent. 
https://doi.org/10.5194/essd-2021-312

Preprint. Discussion started: 5 October 2021

(c) Author(s) 2021. CC BY 4.0 License.

(c) (i)

140 RATE is a rank of deformation rate with estimated boundary values of one and five mm per year, which may not be considered as actual measured slip rates. Slip rate is unlikely to be justified well at low confidence faults so that RATE is meaningless for such faults. Therefore, boundary values of RATE have been chosen to affect primarily high-confidence faults with minimal rate estimation error. However, measurement techniques and their accuracy may vary greatly even in well-studied regions, thus making RATE a qualitative indicator acceptable for regional-scale visualization and analysis.

145 SENS1 and SENS2 represent sense slip motion by its primary and secondary components (Table 1); SENS2 has values only for faults with identified oblique slip. SIDE is a direction of an upthrown side of the fault recorded as cardinal direction with leading “+”.

\subsection{Reference List}

Most of the entries in the database have been collected from published studies, 612 references in total. The reference list

150 represents the database sources as a separate tab-separated text file with the text of brief reference (equal to the domain of the "AUTH" field) and a complete bibliographic reference to the source publication in English and in the language of publication. For data compiled for the World Map of Major Active Faults and never published before it, the reference is supplemented with the name of a researcher responsible for a region containing the fault (e.g., Kozhurin, data 1996). Recent unpublished contributions have reference to the responsible researcher and the year of update.

\section{Source Data}

The database generally inherits the approach and structure of the World Map of Major Active Faults (scale 1:5M, Trifonov and Machette, 1993), although being radically improved in spatial detail and fault parameterization. Those improvements required the compilation of heterogeneous sources, mostly regional maps of active faults and research papers. Due to the amount of processed data, we update any fault zone just to the target detail and resume the processing in rare cases of

160 contradiction between the database and newly published data. We exploited several sources of fault characteristics with methods of data processing vary between them.

The first attempt to collect a global-scale inventory of active faults was the World Map of Major Active Faults that was initiated in 1989 and approved by the International Lithosphere Commission in 1990 as the Project II-2 of the International Lithosphere Program (ILP). The Project was supported by UNESCO as a contribution of the ILP to the UN International

165 Decade of Natural Disaster Reduction and was included in the ILP Global Seismic Hazard Assessment Program in 1993. During that project, our team proposed data representation methods (Trifonov and Machette, 1993) and the database DB96 model for parametrization of active faults (Ioffe and Kozhurin, 1996) based on the software design of Ioffe et al. (1993). This first database of active faults of Eurasia contained about 10,000 objects. These data were published as the active fault maps of Eurasia and Northern and Eastern Africa, 1:10,000,000 (Fig. 3, Trifonov, 2004), Eurasia, 1:5,000,000 (Trifonov, 1997), and in the table format (Trifonov et al., 2002). 


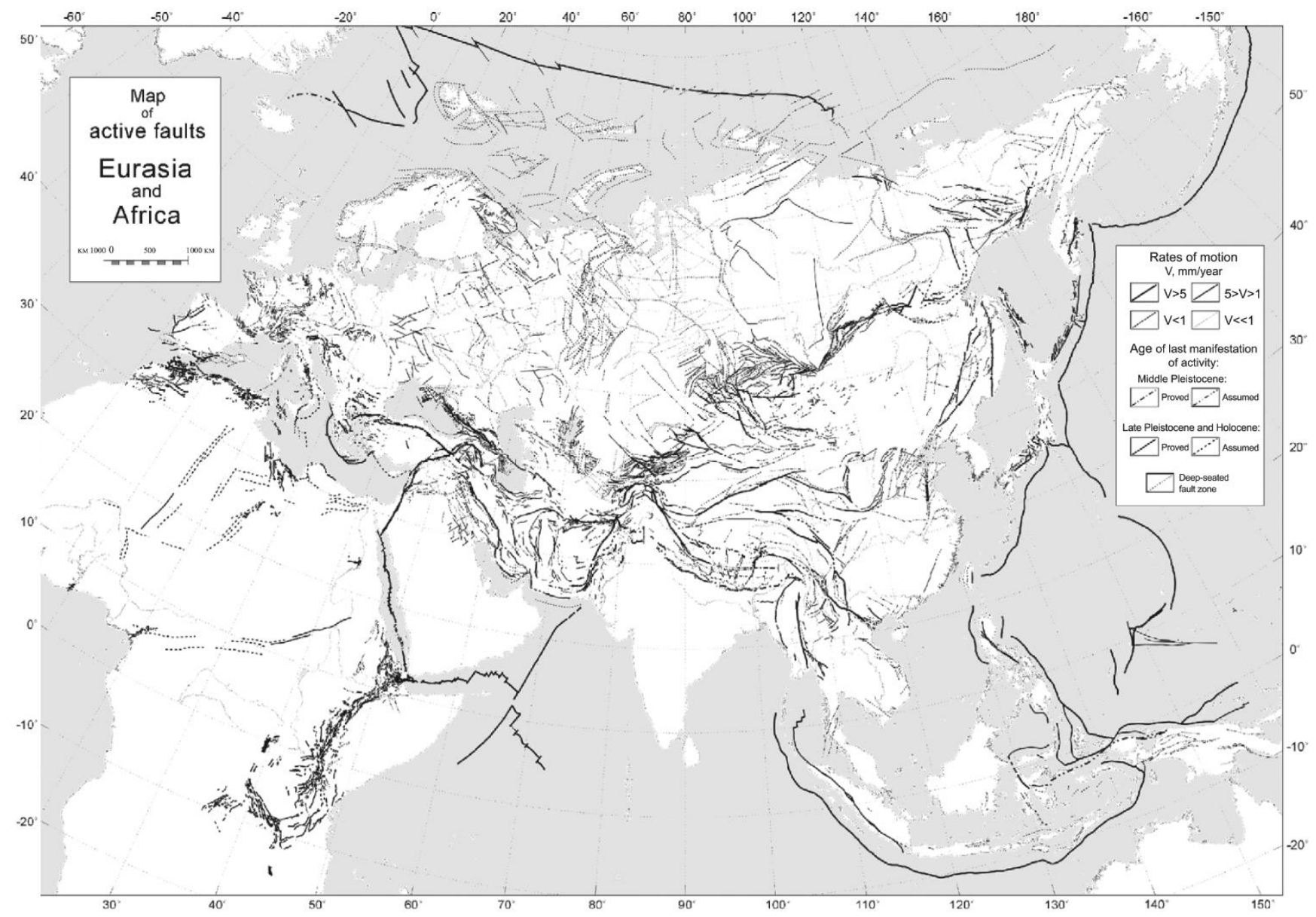

Figure 3. A selection from the World Map of Major Active Faults for Eurasia and Africa (Trifonov, 2004).

In AFEAD, we use the spatial database of the World Map of Major Active Faults as a base layer, referred to as DB96. Its entries were redrawn to comply with the target scale, and the attributes were updated according to the actual database scheme, thus providing a framework for further data collection.

Among the rest of the sources, a large amount of data was collected from region-scale maps and databases of active faults (e.g., Hessami et al., 2003, Basili et al., 2013), both digital and published in hardcopy. Such maps usually bear sufficient information on slip direction and rate as well as generalization level but lack reasoning. Therefore, their processing includes georeferencing, verification of their spatial location against topography, and population of attributes (Fig. 4). CONF is to be set uniform and low, and its elevation requires additional studies at individual faults. 

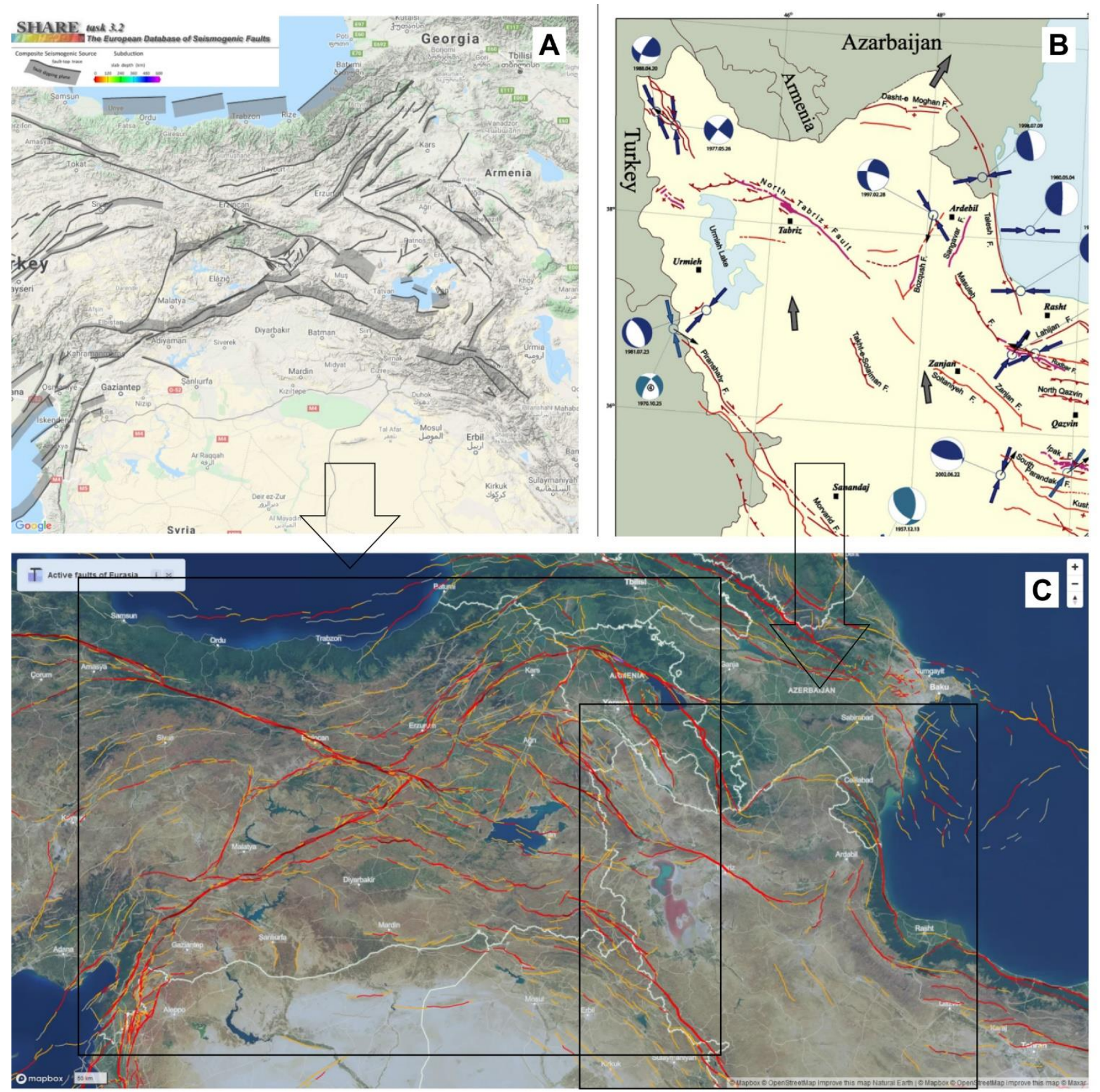

Figure 4. Active faults in Transcaucasia: (a), web-interface of the European database of Seismogenic Faults (Basili et al., 2013); (b), a fragment of the Major Active Faults of Iran Map (Hessami et al., 2003); (c), AFEAD web-interface (http://neotec.ginras.ru/index/mapbox/database_map.html, last access July 17, 2021) for this area.

185 Research papers are the most comprehensive sources considering a particular fault or a fault zone. A standard structure of a research paper provides both parameters of active faults and rationale for it, thus allowing us to assess the reasoning and 
choose the most relevant and accurate data among published. However, the methods and definitions significantly vary in sources. Therefore, they require a thorough analysis and normalization before population (Fig. 5).

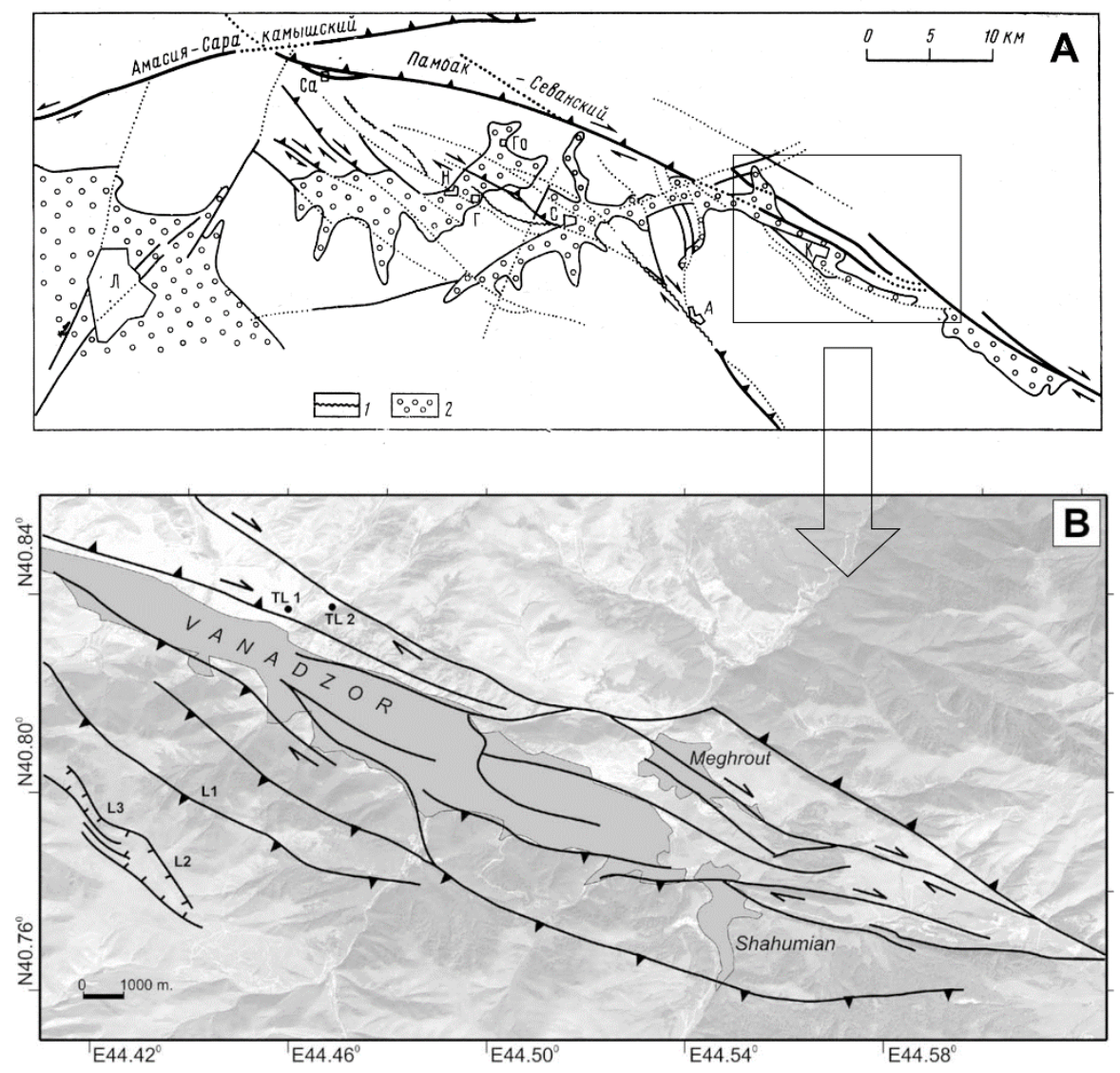

190 Figure 5. Sources for mapping Pambak-Sevan fault near Vanadzor city, Armenia. (a) an initial study of Trifonov et al. (1990), geographical objects and coordinates had been omitted due to Soviet legal requirements; the location of Vanadzor is labeled with K (for its former name Kirovakan) within the box. (b) a more recent georeferenced map (Karakhanian et al., 2004). Both papers affected the location and attributes of the Pambak-Sevan fault in AFEAD, including the object highlighted in Fig 2.

Spatial adjustment and verification of populated fault parameters require complementary sources. The global digital elevation model SRTM V3 and Landsat 7 ETM+ imagery serve as base maps for any spatial processing. Earthquakes are strong evidence of fault activity, so we utilized catalogs of the National Earthquake Information Center (NEIC), U.S. Geological Survey (https://earthquake.usgs.gov/, last access July 30, 2021) and the International Seismological Centre (ISC, http://www.isc.ac.uk/, last access July 30, 2021) to refine the confidence in fault activity (a value of "CONF" field) and, where needed, to specify fault plane geometry and slip sense.

200 Published data have to be supplemented by additional interpretation of remote sensing data to facilitate the uniform detail of the database by adding unpublished objects. In most cases, additional research was required at the spatial boundaries of cited studies (e.g., national borders, limits of a tectonic structure). This contribution significantly improves the spatial pattern of 
active faults in remote areas, mainly in North Asia. Such unpublished entries will be updated as soon as new studies are published, although it is unlikely to occur in the near future for all the entries.

\section{Overview of the Dataset}

\subsection{General characteristics}

The database comprises 46,775 objects - active faults and their segments. Most of them (ca. 42,100) belong to mainland Eurasia, whereas the rest are located on islands or underwater. Active faults tend to group in broad belts (Fig. 1) incorporating minor plates and crustal blocks at margins of tectonic plates. However, active faults were mapped elsewhere across tectonic plates as well. Individual faults are indistinguishable on the continent-scale map, but a fault density map (Fig.

6) shows an even greater contrast between active belts and cratons.

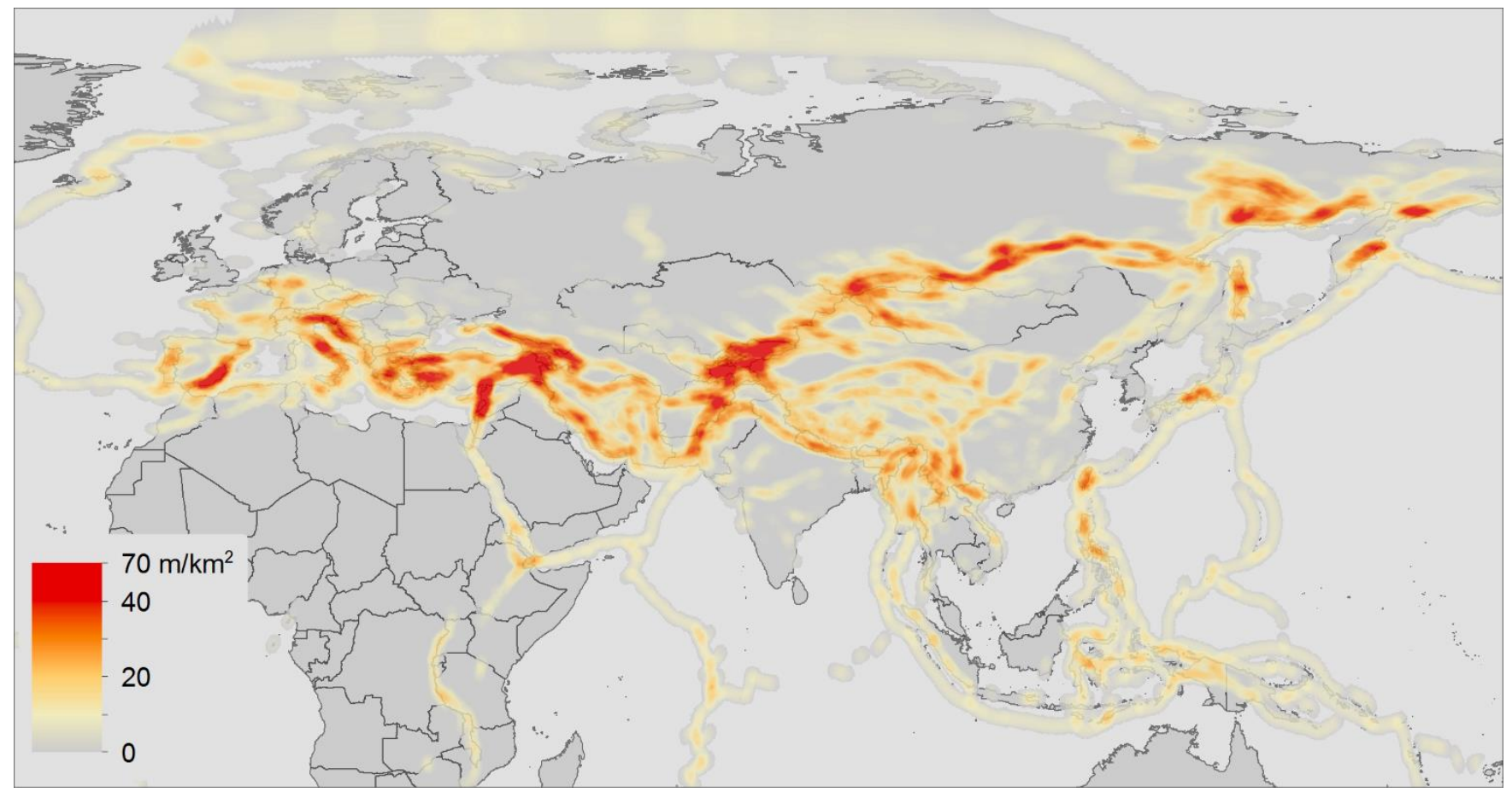

Figure 6. The density of active faults in AFEAD, meters per $\mathrm{km}^{2}$. Low-confidence faults (CONF="D") are omitted.

The mean length of database objects is $22 \mathrm{~km}$, and $90 \%$ of them belong to the range 5-60 km (Fig. 7). Most of the faults longer than $100 \mathrm{~km}$ are underwater, where no detailed data are available. 


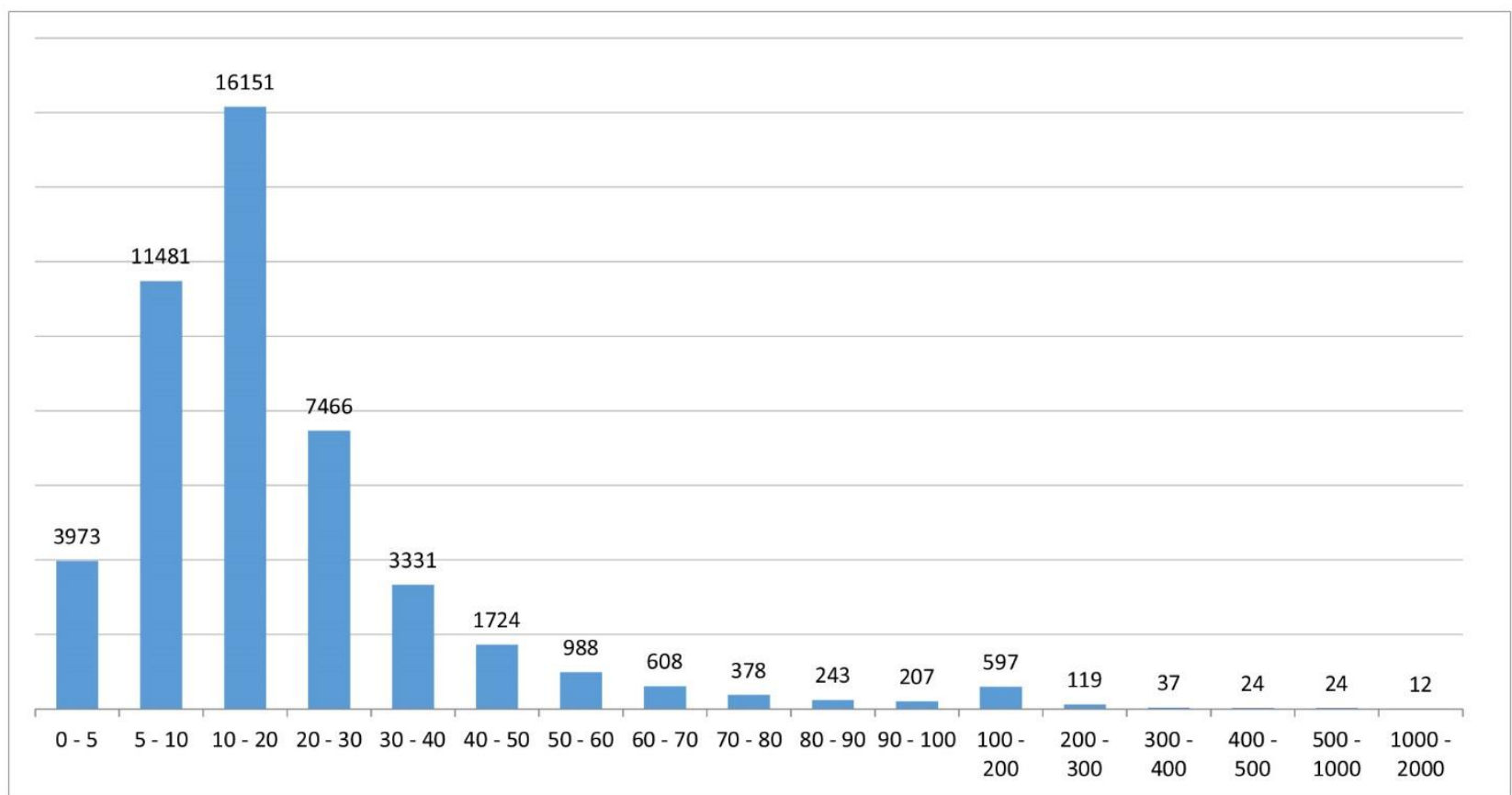

Figure 7. Distribution of AFEAD objects by length.

Within the dataset, $81 \%$ of objects have been published before, including $36 \%$ with two and more sources. The PARM field represents the amount of data yielded by studies. Aside from unpublished, $31 \%$ of entries have empty PARM, most of them originated from maps with no parametrization. Complete descriptions are common in the Western Pacific, Baikal Rift, and Alpine-Himalayan Belt. in the latter, prominent clusters are located in Eastern Mediterranean and Anatolia, Transcaucasia, Iranian mountains, and Tibet region. On the contrary, active faults within cratons typically are poorly studied and lowconfidence, thus representing different approaches of active fault studies.

The intensity of motions along a fault affects two parameters: RATE and CONF (Fig. 8). The former is a natural characteristic, whereas the latter represents the quality and quantity of studies considered the fault (Table 2). Therefore, subsequent researches may elevate CONF, even at slow-moving faults. Most of AFEAD entries (94\%) are slow-moving faults $(\mathrm{RATE}=3)$; all low-confidence $(\mathrm{CONF}=$ "D") and most $\mathrm{CONF}=$ "C" faults fall within this class. Deformation rates exceeding $1 \mathrm{~mm} / \mathrm{yr}$ were identified for $6.2 \%$ of entries; faults exceeding $5 \mathrm{~mm} / \mathrm{yr}$ comprise $1 \%$ of entries. The amount of both $\mathrm{CONF}=$ "A" and CONF="B" faults in RATE classes gradually decrease from slow-moving to fast-moving. 


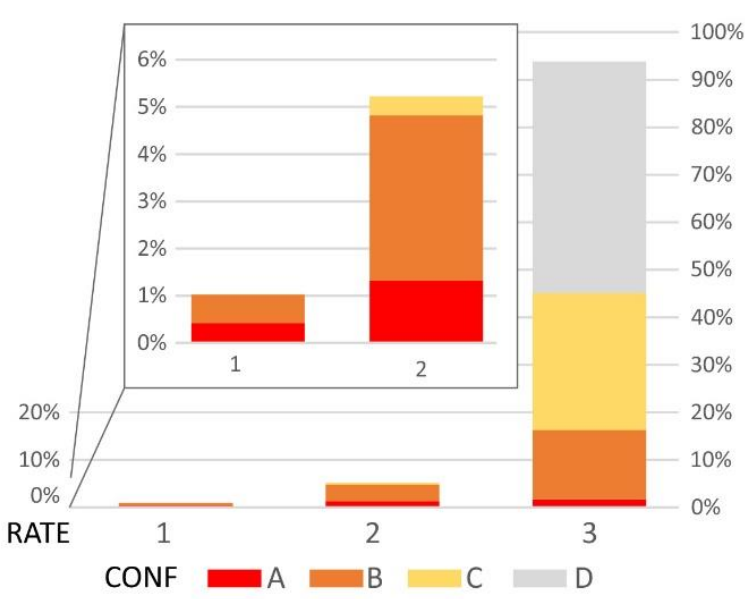

Figure 8. Distribution of AFEAD objects by classes of RATE (horizontal axis) and CONF (color). Inset, zoomed RATE classes 1 and 2.

The most frequent fault sense in AFEAD is reverse (21\%) even considered separately from thrusts (7\%), the normal sense was identified in $17 \%$ of objects, amount of right-lateral and left-lateral faults are almost equal (13\% and 12\%). Dip-slip was identified in $18 \%$ of entries, whereas the sense of slip remains unknown for the rest $11 \%$ of entries. A secondary component is provided for $22 \%$ of entries (Fig. 9).

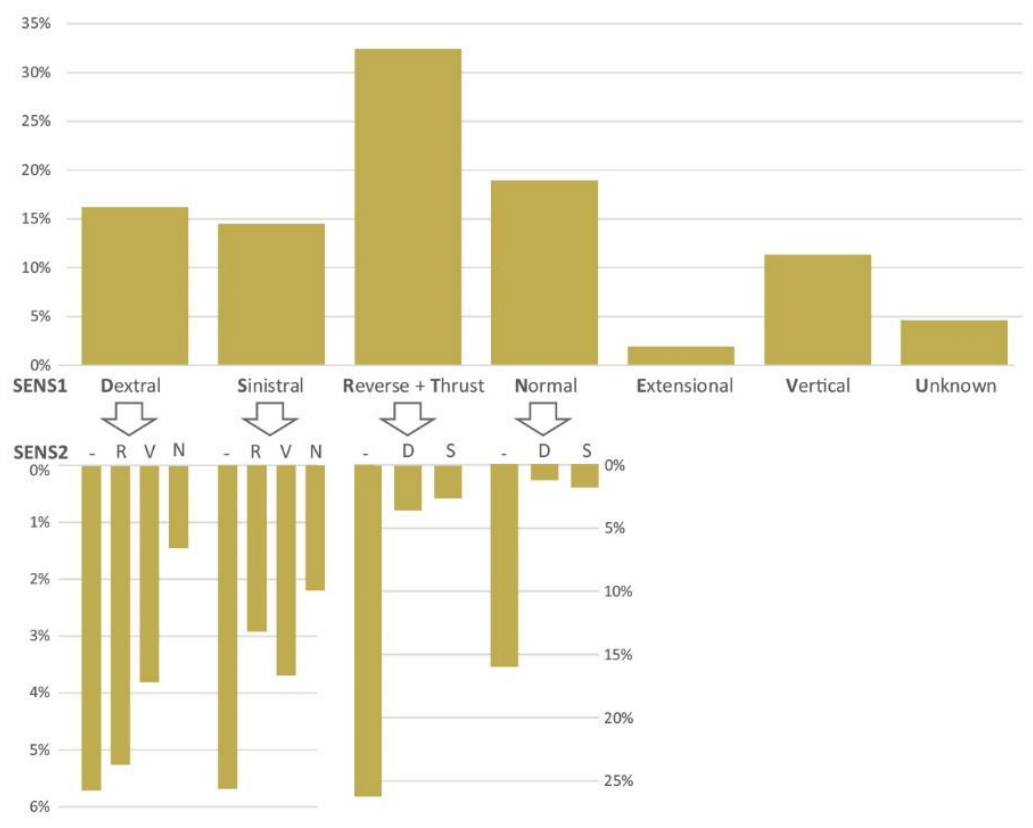

Figure 9. Distribution of AFEAD objects by fault sense: top, SENS1, bottom, SENS2 for each SENS1 value. For sense indices see Table 1. 


\subsection{Regional examples}

To provide a deeper insight into the AFEAD structure and usability, we present two contrast examples from the compressional setting of the Caucasus and the transtensional setting of the Baikal region corresponding to $4^{\circ} \times 6^{\circ}$ map tiles K-38 Tbilisi (http://neotec.ginras.ru/index/datamap/AFEAD_K38_Map.html, last access: July 30, 2021) and N-49 Chita (http://neotec.ginras.ru/index/datamap/AFEAD_N49_Map.html, last access: July 30, 2021).

245 The Caucasus is located at the northern flank of the Alpine-Himalayan collision belt. It has been experiencing compression since the Oligocene (e.g., Nikishin et al., 1998) that, together with mantle geodynamics, built up a high mountain range of the Greater Caucasus and highlands of Transcaucasia south of it. Recent deformation in the area is concentrated at the Main Thrust of the Greater Caucasus and an arcuate system of Zheltorechensky-Sarykamysh, Pambak-Sevan, Garni, and Hanarasar strike-slip fault zones in Transcaucasia (Fig. 10). Minor faults generally follow their pattern, although they are

250 scattered across large areas up to the northern foothills of the Caucasus. In the Greater Caucasus, most of the faults had been identified by the 1980s and published in monographs on broad geological topics (e.g., Milanovsky, 1968, Kogoshvili, 1970) incorporated into DB96. Few works were carried out after the compilation of DB96; thus, the Greater Caucasus area appears to lack state-of-art paleoseismological studies. Transcaucasia had been much less studied until the infamous 1988 Spitak earthquake (Ms =6.7, Bommer and Ambraseys, 1989). The subsequent extensive studies (e.g., Trifonov et al., 1990;

255 Karakhanian et al., 2004) revealed spatial patterns and geodynamic settings of active faulting. Hence, AFEAD entries in Transcaucasia bear much more attributes than those at the Greater Caucasus.

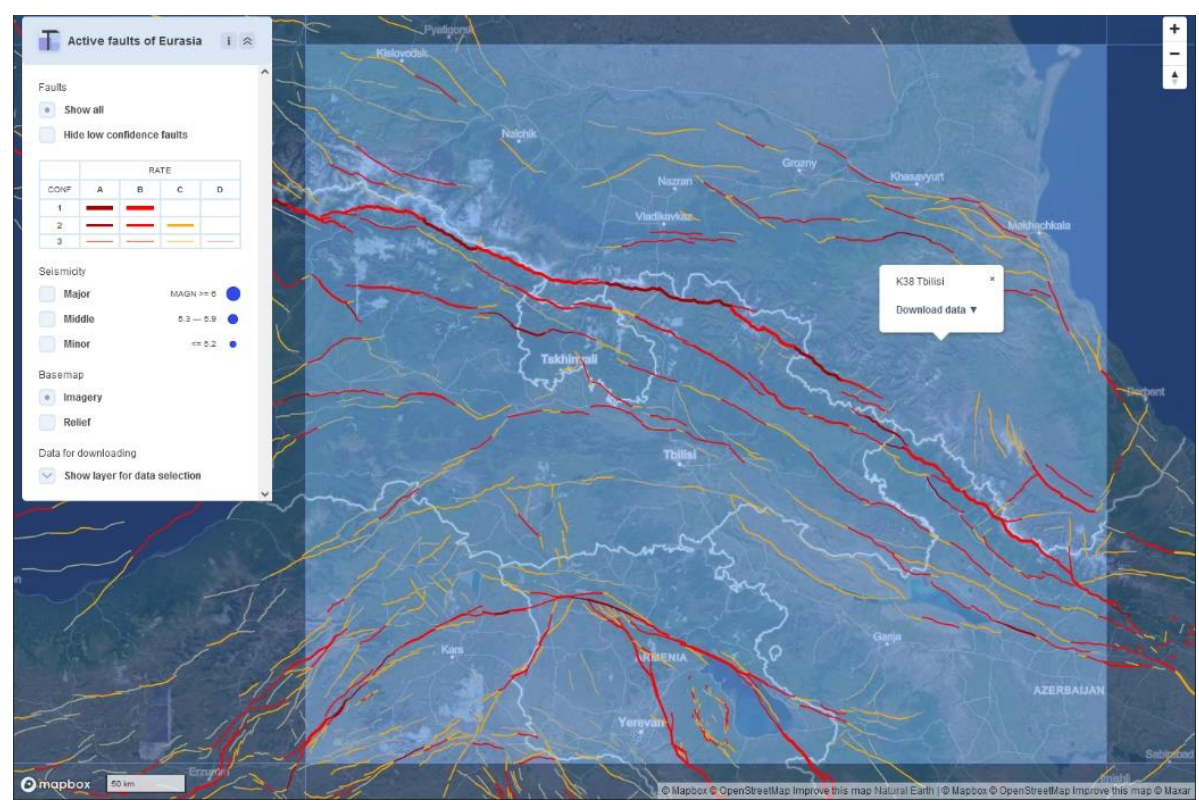

Figure 10. Representation of active faults in the Caucasus by AFEAD web-interface (http://neotec.ginras.ru/index/mapbox/database_map.html, last access July 17, 2021). 
260 Another case of different tectonic settings and research history is the Baikal Rift zone (Fig. 11). It is a linear system of grabens bounded by normal or transtensional faults developing since the Oligocene (e.g., Logatchev and Zorin, 1992). General features of this zone had been identified by the 1980s (Sherman and Levi, 1978; Solonenko, 1977 Logachev, 1984), but intermittent seismicity keeps drawing constant attention to the active faults of the region. In addition to research papers, recent studies have been published as regional data collections: an inventory of paleoseismic sites by Smekalin et al. (2010),

265 the database of Pliocene-Quaternary faults of Southern East Siberia (Lunina et al., 2014), and the Map of Seismotectonics of Eastern Siberia (Imaeva et al., 2015). A compilation of these sources provides uniform input for the AFEAD.

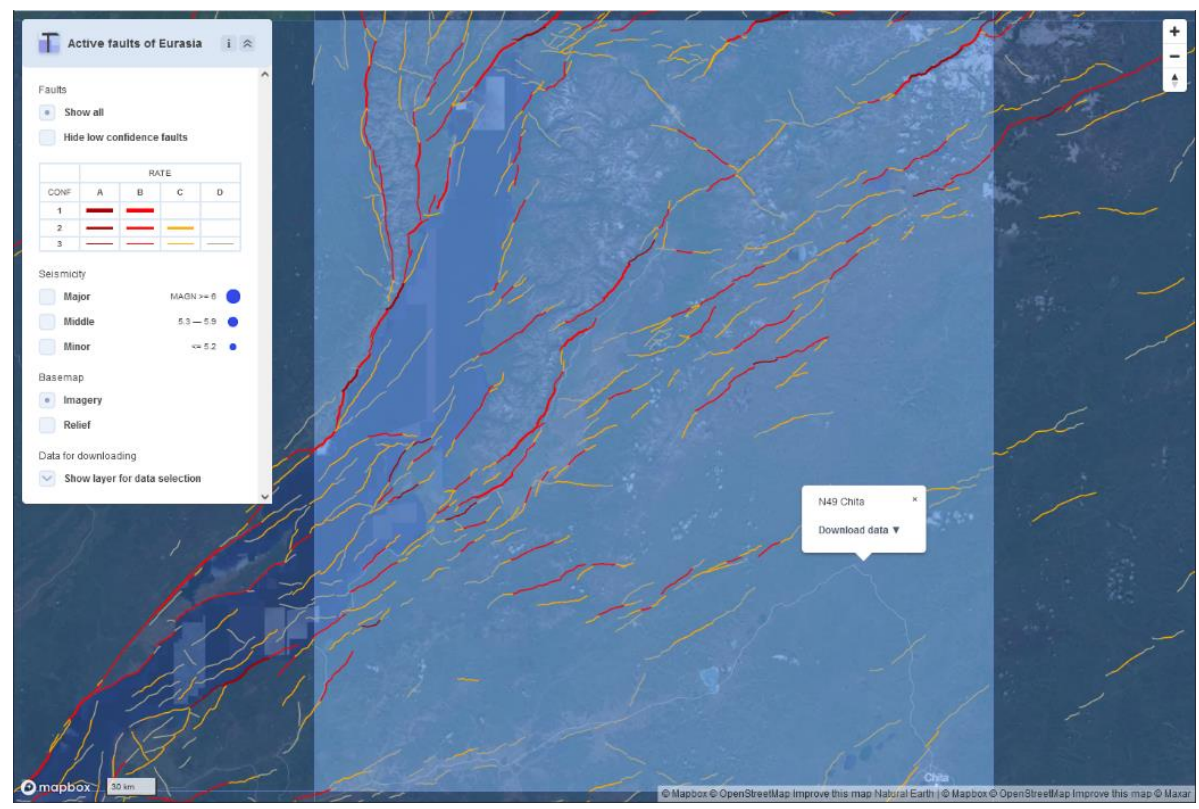

Figure 11. Representation of active faults at the Baikal rift zone by AFEAD web-interface (http://neotec.ginras.ru/index/mapbox/database_map.html, last access July 17, 2021).

\section{Data Access and Further Development}

The main access point to the most recent version of AFEAD is a web map available at http://neotec.ginras.ru/index/mapbox/database_map.html (last access: July 30, 2021). The current data set v.2021 is available at https://doi.org/10.13140/RG.2.2.10333.74726 (Bachmanov et al., 2021). A variety of up-to-date database representations, supplemented by the reference list and explanatory notes, are hosted at

275 http://neotec.ginras.ru/index/english/database_eng.html (last access: July 30, 2021); it includes a raster overview map, raster map tiles designed for print, .kmz, and .shp vector tiles.

Studies considering the AFEAD scheme or its reasoning may refer to this study, DOI of the database, or the initial publication on this topic of Bachmanov et al. (2017). None of them would be an acceptable reference for studies considering fault locations or their parameters; instead, the researcher is advised to cite source studies provided in the AUTH field. 
https://doi.org/10.5194/essd-2021-312

Preprint. Discussion started: 5 October 2021

(c) Author(s) 2021. CC BY 4.0 License.

(c) (1)

280 The presented database AFEAD v.2021 has reached target detail, and no major revisions in the database model and its contents are planned after the completion of this study. However, new versions will be released after the acquisition of recently published data. To ensure data consistency, no direct external contribution to the database is possible. The authors encourage researchers to inform us about missing or recently obtained data via the e-mail of the corresponding author.

\section{Conclusion}

285 AFEAD is the largest and the most comprehensive collection of active faults comprising $~ 47,000$ entries spanning entire Eurasia and adjacent seas. For each entry in the database, its spatial location and characteristics of motions are provided. All spatial data has uniform detail equal to hardcopy maps of scale 1:1M. Attributes of faults store relevant information transferred from sources and derivative parameters generated by the database owners.

The database makes possible a spatial search for local studies. It provides sufficient detail for planning a study of a particular

290 fault system and guides deeper bibliographical investigations if needed. This scenario is particularly significant for vast Central and North Asia areas, where most studies are available only in Russian and hardcopy. Moreover, the database model provides the basis for GIS-based regional and continental-scale integrative studies. The authors suggest that the use of this database will support geodynamic and paleoseismological studies in Eurasia.

\section{Author contributions}

295 EZ and DB conceived and set up the paper. DB, VT, and AK designed the database and compiled the data. SG contributed to database normalization and provided an overview of the dataset. All the authors discussed the study and contributed to the writing of the manuscript.

\section{Competing interests}

The authors declare that they have no conflict of interest.

\section{Acknowledgements}

The authors thank all the colleagues supported the database population. The contributions of N.N. Govorova and G.I. Volchkova made it possible to sustain and develop the database. We are deeply grateful to Dr. A.I. Ioffe, Dr. G.A. Vostrikov, and R.V. Trifonov for their contributions to the ILP II-2 database design strongly affected this study.

\section{Financial support}

305 This research was supported by the Russian Science Foundation, grant no. 17-17-01073-p. State scientific programs have supported data gathering since 1990s, ongoing project no. 0135-2019-0051. 
https://doi.org/10.5194/essd-2021-312

Preprint. Discussion started: 5 October 2021

(c) Author(s) 2021. CC BY 4.0 License.

\section{References}

Active Faults of Eurasia Database (AFEAD) Map View http://neotec.ginras.ru/index/mapbox/database_map.html, last access July 30, 2021.

310 Active Faults of Eurasia Database http://neotec.ginras.ru/index/english/database_eng.html, last access: July 30, 2021.

Bachmanov, D.M., Trifonov, V.G., Kozhurin, A.I. and Zelenin E.A.: AFEAD v.2021, ResearchGate [data set], https://doi.org/10.13140/RG.2.2.10333.74726, 2021.

Bachmanov, D.M., Kozhurin, A.I., and Trifonov, V.G.: The Active Faults in Eurasia Database, Geodynamics and Tectonophysics, 8 (4), 711-736, 2017; doi:10.5800/GT-2017-8-4-0314.

315 Basili R., Kastelic V., Demircioglu M. B., Garcia Moreno D., Nemser E. S., Petricca P., Sboras S. P., Besana-Ostman G. M., Cabral J., Camelbeeck T., Caputo R., Danciu L., Domac H., Fonseca J., García-Mayordomo J., Giardini D., Glavatovic B., Gulen L., Ince Y., Pavlides S., Sesetyan K., Tarabusi G., Tiberti M. M., Utkucu M., Valensise G., Vanneste K., Vilanova S., Wössner J. The European Database of Seismogenic Faults (EDSF) compiled in the framework of the Project SHARE, 2013, http://diss.rm.ingv.it/share-edsf/, doi: 10.6092/INGV.IT-SHARE-EDSF.

320 Bollinger, L., Klinger, Y., Forman, S., Chimed, O., Bayasgalan, A., Munkhuu, U., Davaasuren, G., Dolgorsuren, T., Enkhee, B. and Sodnomsambuu, D.: 25,000 Years Long Seismic Cycle in a Slow Deforming Continental Region of Mongolia, Scientific Reports 17855(11), 2021; https://doi.org/10.1038/s41598-021-97167-w.

Bommer, J.J. and Ambraseys, N.N.: The Spitak (Armenia, USSR) earthquake of 7 December 1988: a summary engineering seismology report, Earthq. Eng. Struct. D., 18(6), 921-925. 1989.

325 Galadini, F., Falcucci, E., Galli, P., Giaccio, B., Gori, S., Messina, P., Moro, M., Saroli, M., Scardia, G. and Sposato, A.: Time intervals to assess active and capable faults for engineering practices in Italy, Eng. Geol., 139,50-65, 2012.

Geologische Rundschau, 43, 1, 1955

Hessami, K., Jamali, F. and Tabassi, H.: Major active faults of Iran. IIEES, Tehran, 2003.

Imaeva, L.P., Imaev, V.S., Grib, N.N., Smekalin, O.P., Kozmin, B.M., Chipizubov, A.V. and Trifomenko, S.V.: Map of

seismotectonics of Eastern Siberia, TI SEFU, Neryungri, 2015.

International Seismological Centre http://www.isc.ac.uk/, last access July 30, 2021.

Ioffe, A.I. and Kozhurin, A.I.: Database of active faults of Eurasia, Earthq. Pred. Res., 5, 431-435, 1996.

Ioffe, A., Govorova, N., Volchkova, G. and Irifonov, R.: Data base of active faults for the USSR area, Geoinformatics, 4(3), 289-290, 1993.

335 Karakhanian, A.S., Trifonov, V.G., Philip, H., Avagyan, A., Hessami, K., Jamali, F., Bayraktutan, M.S., Bagdassarian, H., Arakelian, S., Davtian, V. and Adilkhanyan, A.: Active faulting and natural hazards in Armenia, eastern Turkey and northwestern Iran, Tectonophys., 380(3-4), 189-219, 2004.

Kogoshvili L.V.: Active tectonics of Georgia and its influence to relief, Metsienerba, Tbilisi, 220 pp., 1970 (in Russian).

Kozhurin, A. and Zelenin, E.: An extending island arc: The case of Kamchatka, Tectonophys., 706, 91-102, 2017. 
https://doi.org/10.5194/essd-2021-312

Preprint. Discussion started: 5 October 2021

(c) Author(s) 2021. CC BY 4.0 License.

(c) (i)

340 Kumamoto T.: Long term conditional seismic hazard of Quaternary active faults in Japan, J. Seismol. Soc. Japan, 50, 53-71, 1998 (in Japanese).

Logachev N.I. (ed.): Geology and seismicity of the Baikal-Amur railway zone. Neotectonics, Nauka, Novosibirsk, 1984, 208 pp., 1984 (in Russian).

Logatchev, N.A. and Zorin, Y.A.: Baikal rift zone: structure and geodynamics, Tectonophys, 208 (1-3), 273-286, 1992.

345 Lunina, O.V., Caputo, R., and Gladkov, A.S.: Southern East Siberia Pliocene-Quaternary faults: database, analysis and inference, Geoscience Frontiers, 5, 605-619, 2014.

Map of active faults. Sheet K-38 Tbilisi http://neotec.ginras.ru/index/datamap/AFEAD_K38_Map.html, last access: July 30, 2021.

Map of active faults. Sheet N-49 Chita http://neotec.ginras.ru/index/datamap/AFEAD_N49_Map.html, last access: July 30, 3502021.

Milanovsky E.E.: Neotectonics of the Caucasus, Nedra, Moscow, 1968. 484 pp., 1968 (in Russian).

Nikishin, A.M., Cloetingh, S., Brunet, M.F., Stephenson, R.A., Bolotov, S.N. and Ershov, A.V.: Scythian Platform, Caucasus and Black Sea region: Mesozoic-Cenozoic tectonic history and dymanics, in: Peri-Tethys Memoir 3: stratigraphy and evolution of Peri-Tethyan platforms, edited by: Crasquin-Soleau, S. and Barrier, E. (eds), Mem. Mus. Natn. Hist. Nat., 355 177, Paris, 163-176, 1998.

Rukieh, M., Trifonov, V.G., Dodonov, A.E., Minini, H., Ammar, O., Ivanova, T.P., Zaza, T., Yusef, A., Al-Shara, M. and Jobaili, Y.: Neotectonic map of Syria and some aspects of Late Cenozoic evolution of the northwestern boundary zone of the Arabian plate. J. Geod., 40(2-3), 235-256, 2005.

Schellart, W.P. and Lister, G.S.: The role of the East Asian active margin in widespread extensional and strike-slip 360 deformation in East Asia. J. Geol. Soc., 162(6), 959-972, 2005.

Sherman S.I. and Levi K.G.: Transform faults in the Baikal rift zone and seismicity on its flanks, in: Tectonics and seismicity of the continental rift zones, Nauka, Moscow, 7-185, 1978 (in Russian).

Slemmons, D.B., and dePolo, C.M.: Evaluation of active faulting and associated hazards, in Active tectonics, edited by Wallace, R.E., National Academy Press, Washington, D.C., 45-62, 1968.

365 Smekalin O.P., Chipizubov A.V., Imayev V.S.: Paleoearthquakes in the Pribaikalie: methods and results of dating, Geod Tectonophys, 2010, 1(1), 55-74, 2010 (in Russian).

Solonenko V.P. (ed.): Seismic zonation of the Eastern Siberia and its geologic-geophysical basis, Nauka, Novosibirsk, 1977, 304 pp., 1977 (in Russian).

Trifonov, V.G.: World map of active faults, their seismic and environmental effects, in Historical and Prehistorical 370 Earthquakes in the Caucasus, Kluwer Acad. Publ., Dordrecht, 169-180, 1997.

Trifonov, V.G.: Active faults in Eurasia: general remarks, Tectonophys., 380(3-4), pp.123-130, 2004.

Trifonov, V.G. and Kozhurin, A.I.: Study of active faults: Theoretical and applied implications, Geotectonics, 44(6), 510$528,2010$. 
https://doi.org/10.5194/essd-2021-312

Preprint. Discussion started: 5 October 2021

(c) Author(s) 2021. CC BY 4.0 License.

(c) (1)

Trifonov, V.G. and Machette, M.N.: The world map of major active faults project, Ann. Geophys., 36(3-4), 225-236, 1993.

375 Trifonov, V.G., Karakhanian, A.S., Kozhurin, A.I.: The Spitak earthquake as a manifestation of active tectonics, Geotectonika, 6, 46-60 1990, (in Russian).

Trifonov, V.G., Soboleva, O.V., Trifonov, R.V. and Vostrikov, G.A.: Recent Geodynamics of the Alpine-Himalayan Collision Belt, GEOS, Moscow, 225 pp., 2002 (in Russian).

Ulomov V., Strakhov V. and Giardini D.: Seismic hazard assessment in Northern Eurasia, Ann. Geophys., 36, 3-4, 83-92, 3801993.

USGS Earthquake Hazard Program https://earthquake.usgs.gov/, last access July 30, 2021.

Walker, J.F., Boncio, P., Pace, B., Roberts, G., Benedetti, L., Scotti, O., Visini, F. and Peruzza, L.: Fault2SHA Central Apennines database and structuring active fault data for seismic hazard assessment, Scientific data, 8(1), 1-20, 2021.

Wallace, R.E.: Structure of a portion of the San Andreas rift in southern California, Geol. Soc. Am. Bull., 60(4), 781-806, 1949.

\section{Appendix. Data domain of the PARM field}

Age $=$ Age of the latest dated slip in years BP or units of the geological time scale (e.g. N1 for the Miocene, Q4 for the Holocene).

Signs $=$ Signs of recent fault motion:

390 DF Drape fold,

DT Sharp change of recent deposits thickness,

EC En echelon array of compressional structures,

EQ Earthquake hypocenter,

ER Surface seismic ruptures,

395 ET En echelon array of extensional structures,

FD Surface folding,

FM Earthquake focal mechanism,

FR Linear group of fractures,

GA Gas and hydrochemical anomalies,

400 GD Geodetic surveys,

GP Geophysical data,

HS Historical or archaeological data,

HT Hydrothermal springs,

LS Linear group of landslides or rockfalls,

405 MV Mud volcanism, 
OC Offset river channels,

OD Offset recent deposits,

OT Offset river terraces or alluvial fans,

PS Paleoseismic sites,

410 TS Sharp change of tectonic structure

VC Volcanic chain.

Dating $=$ Dating techniques:

AR Archaeological,

CR Radiocarbon,

415 GC Geological correlation,

HI Historical,

IN Instrumental,

LH Lichenometry,

MC Geomorphological correlation.

420 Layers= Faulted layers of the lithosphere:

S Sedimentary cover,

UC Upper crust,

LC Lower crust,

M Upper mantle.

425 Dip= Dip angle (in degrees), dip direction (cardinal directions), occasionally supplemented with site coordinates or fault part (cardinal directions, $\mathrm{C}$ for central) for which data are relevant.

Depth= Fault depth in km.

Offset= Measured offset at the surface, occasionally supplemented with site coordinates or fault part (cardinal directions, C for central) for which data are relevant.

430 Rake $=$ Rake, the angle between the slip direction and the strike line.

Rate $=$ Average slip rate, $\mathrm{mm} / \mathrm{yr}$, supplemented with time span and occasionally site coordinates or fault part (cardinal directions, $\mathrm{C}$ for central) for which data are relevant. An asterisk $(*)$ indicate geodetic measurements, a double asterisk $(* *)$ seismological measurements.

Ratio $=$ Ratio of strike slip and dip slip.

435 Seism= Parameters of an earthquake occurred at the fault: magnitude, (name,) date, depth.

SeismDepth $=$ Depth range of earthquakes at the fault.

SeismRecur $=$ Mean recurrence interval of earthquakes at the fault.

Sense $=$ Fault slip sense, abbreviated (as in Table 1).

Side $=$ A direction of an upthrown side of the fault. 